\title{
Otomatik Kütle Yüklemeli Pistonlu Basınç Standardı ile Referans Basınç Uygulaması
}

\author{
${ }^{* 1}$ Recep Y1lmaz, ${ }^{2}$ Abdullah Hamarat \\ *1,2 Tübitak UME, Ulusal Metroloji Enstitüsü, Gebze-Kocaeli, Türkiye
}

\begin{abstract}
Özet
Pistonlu basınç standartları alanı yüksek doğrulukta bilinen piston-silindir ünitesi üzerine kütle setleri kullanılarak kuvvet etki ettirilmesi suretiyle referans basınç değerinin elde edilmesi prensibine göre çalışmaktadır. Gerek hidrolik gerekse pnömatik pistonlu basınç standartlarının kullanılmasında en önemli zorluklardan biri her basınç noktasında kütle setlerinin yeniden yüklenmesi veya yeni kütle kombinasyonunun oluşturulmasıdır. Basınç değerlerinin manuel olarak oluşturulması zaman kaybının yanı sıra, operatörden kaynaklanabilecek yanlış yükleme gibi istenmeyen çalışma koşullarına neden olabilmektedir. Bu çalışmada otomatik kütle yüklemeli pistonlu basınç standardı (AMH-38 ile birlikte PG-7601 platformu) tanıtılmakta, bu sistem kullanılarak kalibrasyonun gerçekleştirme aşamaları anlatılmakta ve elde edilen sonuçlar paylaşılmaktadır.
\end{abstract}

Anahtar Kelimeler: Otomatik kalibrasyon, Otomatik ölçüm, Basınç, Mutlak basınç

\begin{abstract}
The piston pressure standards field operates on the principle of achieving the reference pressure value by applying force on the piston-cylinder unit, known as high accuracy, using mass sets. One of the most important difficulties in using hydraulic or pneumatic piston pressure standards is the reloading of mass sets at each pressure point or the creation of a new mass combination. Manual creation of pressure values can cause undesirable operating conditions such as time loss as well as improper loading due to the operator. In this study, we introduce the automatic mass-loaded piston pressure standard (PG-7601 platform with AMH-38), explain the steps of realizing the calibration using this system and share the resulsts we got.
\end{abstract}

Key words: Automatic calibration, Automatic measurement, Pressure, Absolute Pressure

\section{Giriş}

Birinci seviye pistonlu basınç standartları düşük belirsizlik ve yüksek doğruluğa sahip olduklarından ölçüm biliminde tercih edilmektedirler. Pistonlu basınç standartları kullanılarak basınç oluşturmak için belirli bir kütle seti kullanılmaktadır. Bu şekilde basınç oluşturulurken karşılaşılan en önemli güçlüklerden biri kütle setlerinin piston üzerine yüklenme biçimidir. Cihazın en yüksek çalışma aralığına ulaşmak için kütle setinin içinde bulunan tüm kütleleri sırasıyla piston üzerine yerleştirmek gerekmektedir. Bu da AMH (Automated Mass Handling System) ile birlikte kullanılan PG-7601 platformunun manuel yüklenmesi durumunda 6 kg'lık kütleler ile toplamda 38

*Sorumlu Yazar: Adres: Tübitak UME, Ulusal Metroloji Enstitüsü, Gebze-Kocaeli, Türkiye. E-mail adres: yilmaz.recep@tubitak.gov.tr, Telefon:+902626795000 
kg ağırlık değeri elde etmek için tüm kütlelerin sırasıyla sistem üzerine yüklenmesi anlamına gelmektedir. Bu işlem her bir basınç değeri için ayrı ayrı uygulanmaktadır. Bu şekilde her bir basınç noktası için ayrı ayrı oluşturulan basınç değerinde kullanılan kütle setlerinin yüklenme aşaması hem fiziksel güç gerektirmekte hem de oldukça zaman almaktadır. Bu durumun yanı sıra mutlak olarak yapılan ölçümlerde her bir basınç noktası için sistem vakumlanmakta ve artık gaz basıncı değerinin belli bir seviyeye inmesi beklenmektedir. Bu sebeplerden ötürü pistonlu basınç standartları ile yapılan kalibrasyonlar, kalibratörler ile gerçekleştirilen kalibrasyonlara nazaran daha fazla zaman almaktadır. Zaman kayıplarını en aza indirmek ve maliyetlerin düşürülmesi için TÜBITTAK UME Basınç Laboratuvarı'nda otomatik kalibrasyona yönelik çalışmalar gerçekleştirilmiştir. Bu kapsamda ikinci seviye basınçölçer cihazlarının ve kalibratörlerin mutlak ve bağıl modda kalibrasyonları birinci seviye pistonlu basınç standartları kullanılarak tam otomatik olarak gerçekleştirilmektedir. Bu çalışmada otomatik kütle yüklemeli pistonlu basınç standardı (AMH-38 ile birlikte PG-7601 platformu) tanitılacak ve bu sistem kullanılarak kalibrasyonun gerçekleştirme aşamaları anlatılacak ve elde edilen sonuçlar paylaşılacaktır [1-4].

\section{AMH (Automated Mass Handling System) Pistonlu Basınç Standardı}

AMH-38 ve PG7601 platformu $7000 \mathrm{~Pa}-7 \mathrm{MPa}$ aralığında bağıl ve mutlak basınç ölçümleri için kullanılan otomatik kütle yüklemeli pistonlu basınç standardıdır (Şekil 1). AMH sistemi, PG7601 terminalinden veya PG7601'in COM1 veya IEEE-488 arabiriminden gelen kütle veya basınç girişlerine yanıt olarak otomatik olarak kütle değerlerinin yüklenmesini ve boşaltılmasını sağlar. AMH sistemi, kütleleri PG7601 pistonundan kaldırır, yüklenecek kütleleri seçer ve seçilen kütleleri tekrar pistonun üzerine yerleştirir. Bu, pnömatik ve elektriksel çalıştırma donanımı kullanılarak gerçekleştirilir.

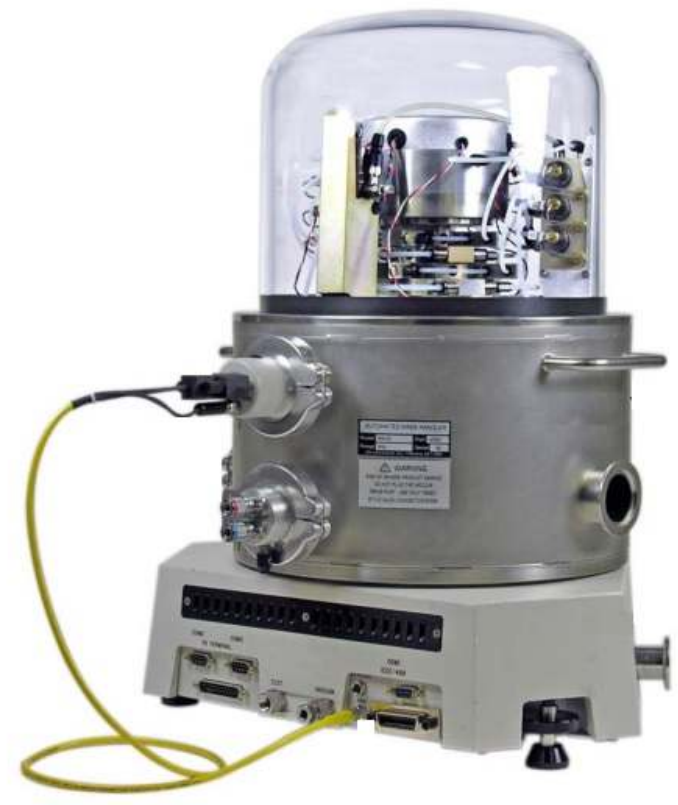

Şekil 1. AMH-38 ve PG7601 Platformu [1, 4] 
Sistemde 0,35 MPa, 1,75 MPa ve $7 \mathrm{MPa}$ olmak üzere farklı çalışma aralıklarında 3 adet pistonsilindir ünitesi kullanılabilmekte olup bağıl ve mutlak basınç ölçümleri yapılabilmektedir (Şekil 2). Sistem ile birlikte kullanılan "Compass for Pressure" yazılımı aracılığıyla ölçümler tam veya yarı otomatik olarak gerçekleştirilmektedir.
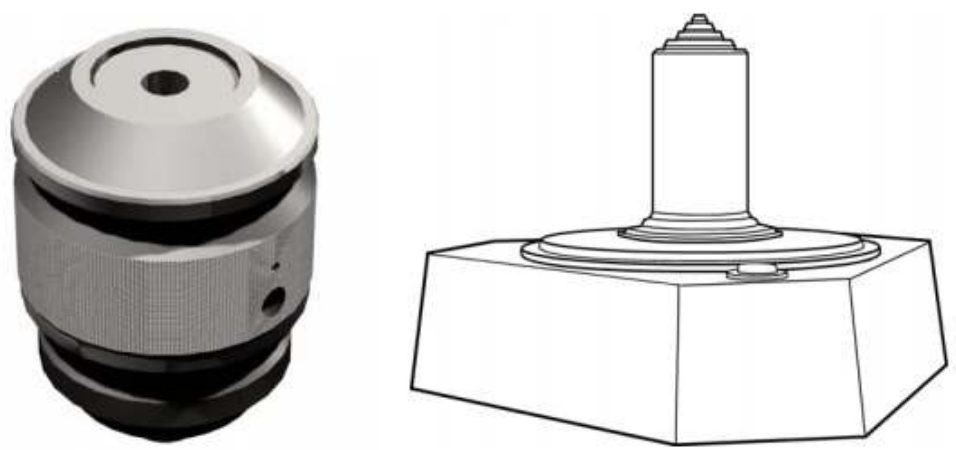

Şekil 2. Kullanılan Piston ve PG-7601 Platform $[1,3]$

Sistemin en önemli bölümlerinden biri AMH (Automated Mass Handling) kısmıdır (Şekil3). Bu bölümde pistonlu basınç standardı üzerine yerleştirilen kütlelerinin istenilen basınç değerlerinde kombinasyonunu sağlayan selenoid valfler ve kütleleri kaldıran pimler mevcuttur. Kullanılan yazılım aracılığıyla kütle seti kombinasyonu komutu bu bölüme gelir ve kütle kaldırıcı pimler uygun konuma gelerek sadece seçili kütleleri piston-silindir ünitesi üzerine yükler. Her basınç değeri için sistem uygun kütle kombinasyonunu seçer ve uygular [2].

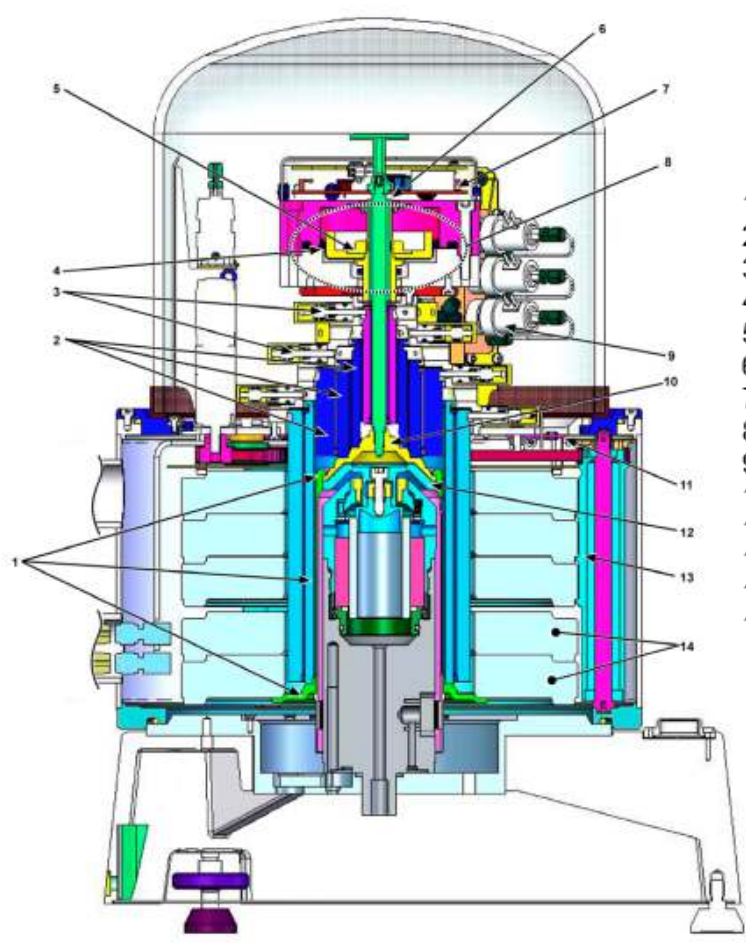

1. kütle taşıyıc ı

2. elektronik kontrol cihazı

3. kütle kaldırma mili

4. pnömatik kaldırıcı hacim

5. çoklu kütle kaldırma manifoldu

6. çoklu kütle seçici pin

7. kütle seti

8. piston-silindir ünitesi

9. çoklu kütle tablası

10. ana kütle sütunu hareket kayışı

11. ana kütle seçici çubukları

12. ana kütleler

13. kütle taşıyıcısı

14. standart PG7000 platformu

Şekil 3. AMH-38 Sistem Elemanları [1, 3] 
AMH-38 bölümünün sorunsuz çalışabilmesi için en az $275 \mathrm{kPa}$ (40 psi) gaz basıncı ile beslenmesi gerekmektedir. Basıncın otomatik oluşturulmasını sağlayan PPC (Pneumatic Pressure Controller) ile iletişim halinde olmalıdır. PPC aynı zamanda piston-silindir platformu ile de iletişim kurmaktadır. Piston-silindir ünitesinin sıcaklı̆̆ı, ortam koşulları, ve referans basıncın hesaplanabilmesi için gerekli tüm parametreler "Compass for Pressure" yazılımı üzerinden okunabildiği gibi, platforma bağlı olan terminal üzerinden de okunabilmektedir. Kalibrasyonu yapılacak test cihazı pistonlu basınç standardı platformu üzerinde bulunan çıkışa doğrudan bağlı olup test cihazı değerleri kalibrasyon programından okunabilmektedir. Tüm sistem tam otomatik olarak çalışabilmekte olup, kalibrasyon sonuçlarının değerlendirilmesi de program üzerinden gerçekleştirilebilmektedir [2].

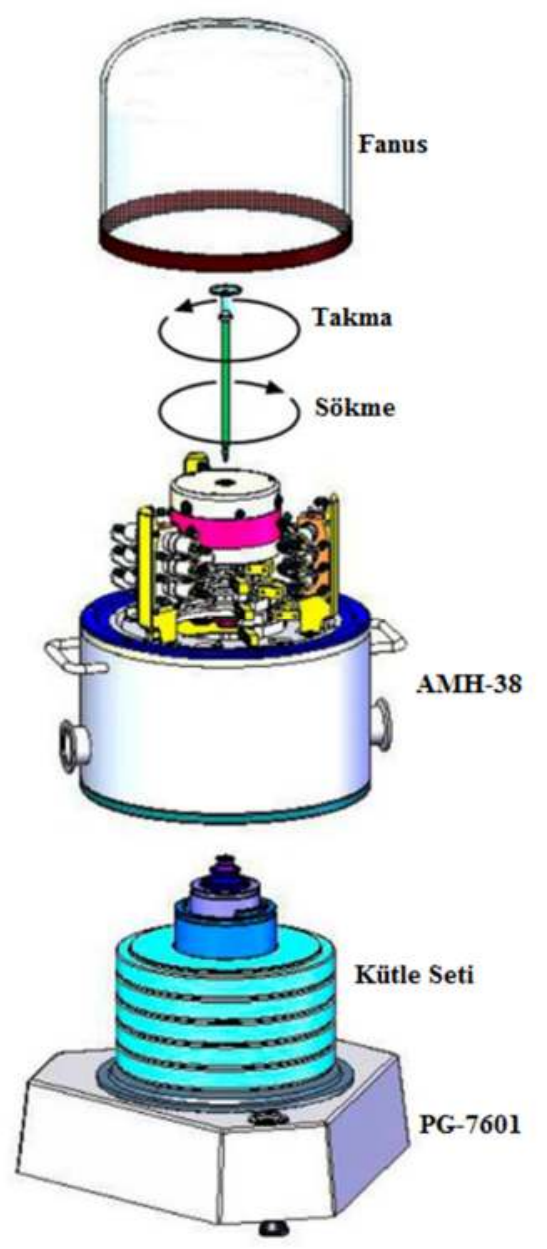

Şekil 4. AMH-38 Montaj ve Demontaj1 [1]

AMH ile ölçüme başlamadan önce kalibrasyon işlemi gerçekleştirilecek test cihazı ölçüm aralığı için uygun bir piston silindir ünitesi PG-7601 platformu üzerine yerleştirilmelidir. Bu aşamada 
öncelikle kütle kaldırma mili saat yönünde döndürülerek sökülür ve AMH-38, PG-7601 platformu üzerinden yan taraflardaki tutma kollarından tutularak kaldırılır. Daha sonra sirasıyla en üstteki küçük silindirik kütleden başlanarak kütleler sistem üzerinden boşaltılır. Yapılacak ölçüme göre seçilen piston-silindir ünitesi platform üzerine çevirerek yerleştirilir. Son olarak sırasıyla yardımcı kütle taşıyıc1, kütle taşıyıc1, 1,2,3,4,5 numaralı temel kütle diskleri, büyükten küçüğe doğru silindirik yardımcı kütleler piston üzerine yüklenir (Şekil 5) ve AMH-38 platform üzerine tekrar yerleştirilerek kütle taşıma mili takılır. Mutlak ölçümlerde AMH-38 üzerine fanus yerleştirilmesi gerekmektedir (Şekil 4).

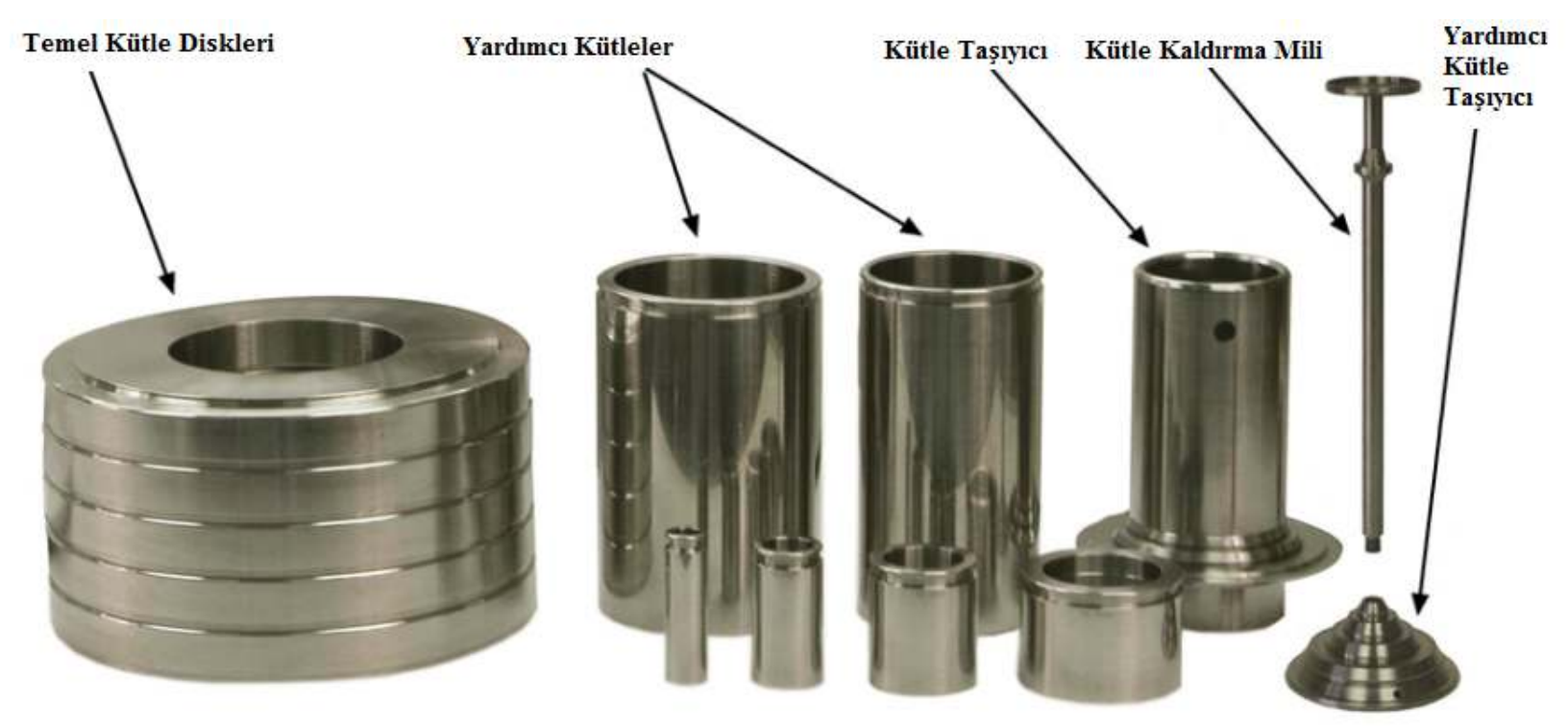

Şekil 5. AMH Sisteminde Kullanılan Kütle Seti [1, 4]

Tübitak UME Basınç Laboratuvarında gerçekleştirilen bir test cihazı kalibrasyonu için oluşturulan kalibrasyon düzeneği Şekil 6'da gösterilmiştir. Yapılacak ölçümün mutlak modda olması istendiğinden AMH-38 üzerine fanus yerleştirilmiştir. Sistem çalıştırılmadan önce vakum pompaları ile kabin içindeki gaz boşaltılmakta ve vakum ortamı elde edilmektedir. Vakumlama miktarı bir diğer deyişle fanus içindeki artık gaz miktarı AMH-38 sistemi ile ölçülebildiği gibi şekilde görüldüğü üzere ilave bir vakum ölçer vasıtası ile de belirlenebilir ve referans basınç hesabına doğrudan dahil edilir. Dikkat edilmesi gereken bir diğer hususta test cihazı sensör girişi ile AMH-38 referans seviyesinin aynı olmasıdır. Eğer seviye farkı varsa ölçülmeli ve hesaba eklenmelidir. AMH-38 ve Compass for Pressure yazılımı üzerinden gerekli seçimler ve ayarlamalar gerçekleştirildikten sonra sistem çalıştırılarak veriler otomatik olarak alınmakta ve kaydedilmektedir. 


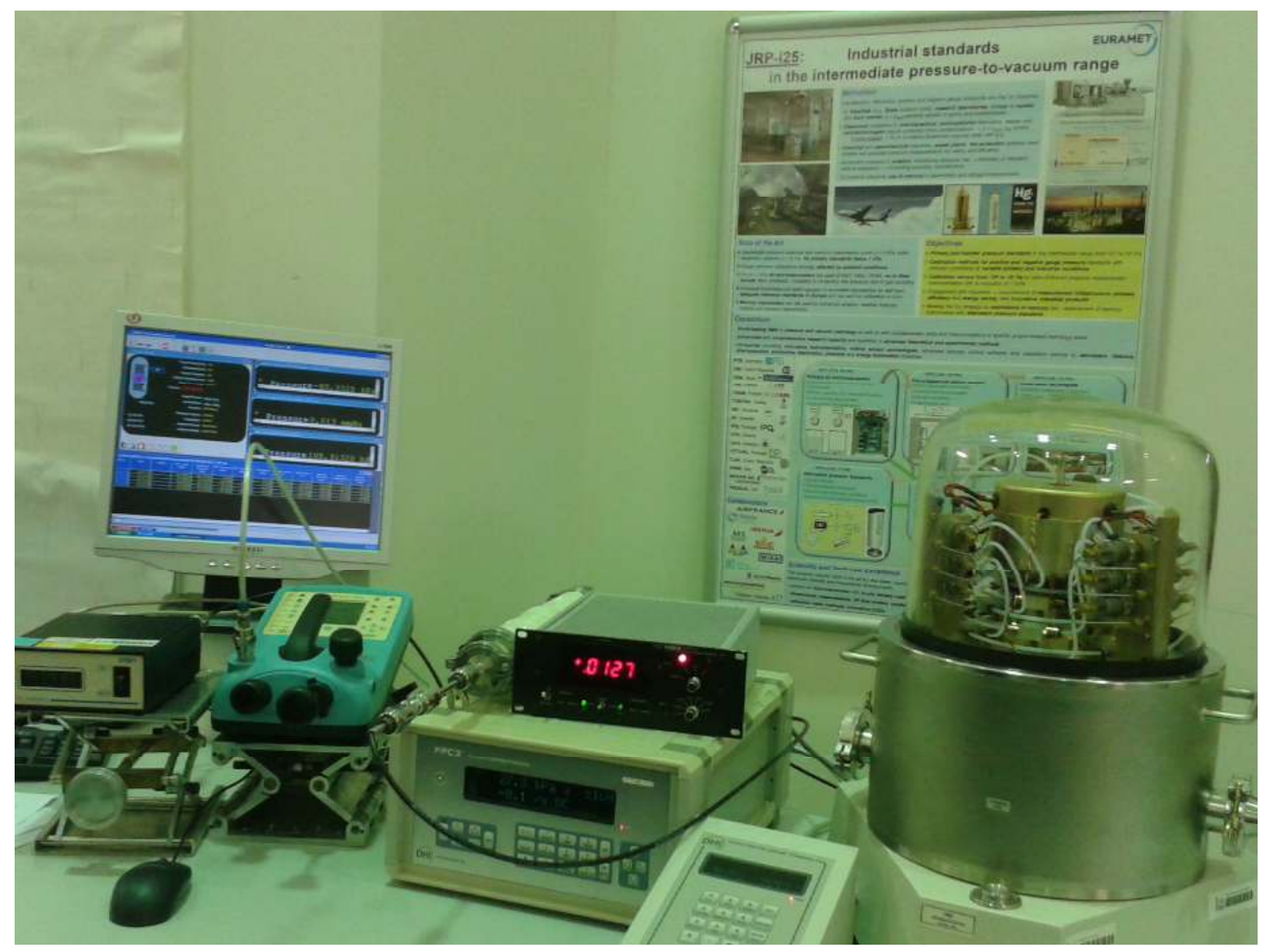

Şekil 6. Örnek Bir Kalibrasyon Düzeneği

Bu kalibrasyon için kullanılacak parametreler ve yöntem şu şekilde olacaktır [5-6];

- Ölçüm aralığı

- Kalibrasyon modu

- Nokta Sayis1

- Çevrim Sayıs1

- Ortam Sicaklığı

- Ortam Bağıl Nemi

- Kullanilan Gaz
$: 0,1$ bar $-1,2$ bar $(1$ bar $=100000 \mathrm{~Pa})$

: Mutlak

: 20 Nokta / Çevrim (10 Nokta Artan, 10 Nokta Azalan)

$: 3$ Çevrim

$: 20 \pm 1{ }^{\circ} \mathrm{C}$

$: 50 \pm 25 \%$ rh

: Azot gazı

\section{Kalibrasyon Sonuçları}

Yüksek doğrulukta basınç standardı kullanılarak karşılaştırma metoduyla gerçekleştirilen kalibrasyon öncesi cihaz açık durumda en az bir saat laboratuvar şartlarında bekletilmiştir. Veriler alınmadan önce cihaz maksimum ve minimum basınç aralığında üç kez çalıştırılarak sistemin basınç altında alıştırılması yapılmıştır. Artan ve azalan yönlerde çevrimler alınmıştır. Basınç ortamı olarak azot gazı kullanılmıştır. Cihaz için referans basınç seviyesi olarak bağlantı noktası seçilmiş 
ve cihaz yatay konumda kalibre edilmiştir. "Compass for Pressure" programı aracılığı ile elde edilen kalibrasyona ait ölçüm verileri Tablo 1'de verilmiştir. Bu veriler ile her bir nokta için referans basınç değeri ve belirsizlik değeri hesaplanmış ve sonuçlar Tablo 2'de gösterilmiştir [2, 5, $6]$.

Tablo 1. AMH-38 ile Yapılan Kalibrasyon ile "Compass for Pressure" Programından Elde Edilen Ölçüm Verileri (Tek Çevrim İçin)

\begin{tabular}{|c|c|c|c|c|}
\hline Set Point & DUT Pressure & Reference Temp & Reference Mass & Reference Vacuum \\
\hline bar & bar & ${ }^{\circ} \mathrm{C}$ & $\mathrm{kg}$ & $\mathrm{Pa}$ \\
\hline 0,1 & 0,0984 & 21,44 & 0,996681 & 1,4 \\
\hline 0,2 & 0,19929 & 21,44 & 2,001398 & 1,4 \\
\hline 0,3 & 0,30018 & 21,45 & 3,007522 & 1,5 \\
\hline 0,4 & 0,39976 & 21,464 & 3,995856 & 1,5 \\
\hline 0,5 & 0,50028 & 21,49 & 5,000141 & 1,5 \\
\hline 0,6 & 0,60099 & 21,54 & 6,006697 & 1,5 \\
\hline 0,7 & 0,70267 & 21,57 & 7,029113 & 1,5 \\
\hline 0,8 & 0,8031 & 21,62 & 8,033398 & 1,5 \\
\hline 1 & 1,00419 & 21,675 & 10,044239 & 1,5 \\
\hline 1,2 & 1,20421 & 21,73 & 12,038697 & 1,5 \\
\hline 1,2 & 1,20421 & 21,76 & 12,038697 & 1,5 \\
\hline 1 & 1,00419 & 21,81 & 10,044239 & 1,5 \\
\hline 0,8 & 0,8031 & 21,86 & 8,033398 & 1,415 \\
\hline 0,7 & 0,70267 & 21,92 & 7,029113 & 1,4 \\
\hline 0,6 & 0,60099 & 21,97 & 6,006697 & 1,4 \\
\hline 0,5 & 0,50028 & 22,06 & 5,000141 & 1,4 \\
\hline 0,4 & 0,39976 & 22,112 & 3,995856 & 1,4 \\
\hline 0,3 & 0,30018 & 22,227 & 3,007522 & 1,4 \\
\hline 0,2 & 0,19928 & 22,252 & 2,001398 & 1,4 \\
\hline 0,1 & 0,09839 & 22,322 & 0,996681 & 1,3 \\
\hline
\end{tabular}


Tablo 2. AMH-38 ile Yapılan Kalibrasyon Ölçüm Sonuçları

\begin{tabular}{|c|c|c|c|c|c|c|c|}
\hline \multicolumn{4}{|c|}{ Artan Basınç Değerlerinde } & \multicolumn{3}{c|}{ Azalan Basınç Değerlerinde } \\
\hline $\begin{array}{c}\text { Referans } \\
\text { Basınç }\end{array}$ & $\begin{array}{c}\text { Test } \\
\text { Basınc1 }\end{array}$ & $\begin{array}{c}\text { Hata } \\
\text { Değeri }\end{array}$ & Belirsizlik & $\begin{array}{c}\text { Referans } \\
\text { Basınç }\end{array}$ & $\begin{array}{c}\text { Test } \\
\text { Basınc1 }\end{array}$ & $\begin{array}{c}\text { Hata } \\
\text { Değeri }\end{array}$ & Belirsizlik \\
\hline mbar & mbar & mbar & mbar & mbar & mbar & mbar & mbar \\
\hline 99,65 & 98,39 & $-1,26$ & 0,01 & 99,65 & 98,39 & $-1,26$ & 0,01 \\
\hline 200,09 & 199,29 & $-0,81$ & 0,01 & 200,09 & 199,28 & $-0,81$ & 0,01 \\
\hline 300,67 & 300,18 & $-0,49$ & 0,01 & 300,67 & 300,18 & $-0,49$ & 0,01 \\
\hline 400,06 & 399,76 & $-0,30$ & 0,01 & 400,06 & 399,76 & $-0,30$ & 0,01 \\
\hline 500,46 & 500,28 & $-0,18$ & 0,02 & 500,46 & 500,28 & $-0,18$ & 0,02 \\
\hline 601,09 & 600,99 & $-0,10$ & 0,02 & 601,08 & 600,98 & $-0,10$ & 0,02 \\
\hline 702,71 & 702,67 & $-0,04$ & 0,02 & 702,71 & 702,66 & $-0,04$ & 0,02 \\
\hline 803,11 & 803,10 & 0,00 & 0,02 & 803,11 & 803,10 & $-0,01$ & 0,02 \\
\hline 1004,13 & 1004,19 & 0,06 & 0,03 & 1004,13 & 1004,19 & 0,06 & 0,03 \\
\hline 1204,10 & 1204,21 & 0,11 & 0,03 & 1204,10 & 1204,21 & 0,11 & 0,03 \\
\hline
\end{tabular}

Not: Hesaplarda 1 mbar $=100$ Pa olarak kullanılmıştır.

Referans Basınç : Kalibrasyon sırasında kullanılan referans cihazda oluşturulan basınç değerlerinin ortalamasıdır.

Test Basıncı $\quad$ : Kalibre edilen cihazdan okunan değerlerin ortalamasıdır.

Hata Değeri : Referans cihazdan uygulanan basınç değerleri ile kalibre edilen cihazdan okunan basınç değerleri arasındaki farktır. Aşağıdaki formül kullanılarak her basınç noktası için hesaplanır.

Hata Değeri $=$ Test Basıncı - Referans Basınç

\section{Tartışma ve Sonuçlar}

Pistonlu basınç standartları kullanılarak basınç oluşturmak için kütle setleri kullanılmakta ve konvansiyonel yöntemlerde karşılaşılan en önemli güçlüklerden biri kütle setlerinin piston üzerine yüklenmesidir. Cihazın en yüksek çalışma aralığına ulaşmak için kütle setinin içinde bulunan tüm kütleleri sırasıyla piston üzerine yerleştirmek hem fiziksel güç gerektirmekte hem de oldukça zaman almaktadır. Bu işlem her bir basınç değeri için ayrı ayrı uygulanmaktadır. Bu durumun yanı sıra yine konvansiyonel yöntemlerle mutlak olarak yapılan ölçümlerde her bir basınç noktası için sistem vakumlanmakta ve artık gaz basıncı değerinin belli bir seviyeye inmesi beklenmektedir. Bu çalışma için yapılan kalibrasyon işlemi AMH-38 ve PG-7601 platformu kullanılarak gerçekleştirildiğinden kalibrasyon işlemi gerekli ayarlamalar yapıldıktan sonra 3 çevrim artan ve azalan yönde veriler alınacak biçimde tam otomatik olarak gerçekleştirilmiş, manuel olarak vakumlama ve kütle yükleme işlemlerinden kaynaklanan zaman kayıpları yok edilmiş ve maliyetlerin düşürülmesi sağlanmıştır. 
Birinci seviye pistonlu basınç standartları düşük belirsizlik ve yüksek doğruluğa sahip olduklarından dolayı ölçüm biliminde bu sistemler sıklıkla tercih edilmektedir. Bununla birlikte bu metrolojik vasıflar yerine getirilirken gerekli olan yüksek hassasiyet isteyen kullanılma biçimi kütlelerin yüklenme zorluğu ve harcanan zaman açısından bazı dezavantajlar içermektedir. Tübitak UME Basınç Laboratuvarı'nda ülke için önemli kuruluşların ve endüstrinin ölçüm ve kalibrasyon ihtiyaçlarının karşılanmasında zamanın verimli kullanılması ve daha hassas sonuçlar elde etmek için mevcut klasik pistonlu basınç standardı yerine tam otomatik AMH-38 cihazı kullanılmış ve klasik pistonlu basınç standardı kullanılarak gerçekleştirilen kalibrasyonlara nazaran zaman kayıpları yok edilmiş ve buna bağlı olarak maliyetlerin düşürülmesi sağlanmıştır. Böylece pistonlu basınç standardı kullanımında dezavantaj olarak ortaya çıkan bu unsurlar ortadan kaldırılmıştır [2, $5,6]$.

\section{Kaynaklar}

[1] AMH-38 $8^{\mathrm{TM}} / \mathrm{AMH}-100^{\mathrm{TM}}$ Automated Mass Handling System for PG7000 Piston Gauges Operation and Maintenance Manual, DH Instruments; 2007

[2] Koçaş İ, Durgut Y. VII. Ulusal Ölçüm Bilim Kongresi Bildirileri. 2008;535-539

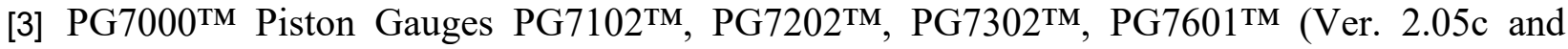
Higher) Operation and Maintenance Manual; 2011

[4] PG-7000-AMH Automated Mass Handling for PG7000 ${ }^{\mathrm{TM}}$ Piston Gauges, Fluke (USA); 2010

[5] BAS1 Analog ve Sayısal Göstergeli Basınç Ölçerlerin ve Basınç Dönüştürücülerinin Kalibrasyonu Eğitim Dokümanı, TÜBİTAK-UME; 2006

[6] BAS2 Pistonlu Basınç Standartlarının Karşılaştırma Metoduyla Kalibrasyonları Eğitim Dokümanı, TÜBİTAK-UME; 2003 